\title{
INFORMAÇÃO, COMUNICAÇÃO E INOVAÇÃO: GESTÃO DA INFORMAÇÃO PARA INOVAÇÃO EM UMA ORGANIZAÇÃO COMPLEXA
}

\author{
INFORMACIÓN, COMUNICACIÓN E INNOVACIÓN: GESTIÓN DE LA \\ INFORMACIÓN PARA INNOVACIÓN EN UNA ORGANIZACIÓN \\ COMPLEJA
}

\begin{abstract}
Clóvis Ricardo Montenegro de Lima - clovis.mlima@uol.com.br Doutor em Administração na EAESP-FGV e Doutor em Ciência da Informação no IBICT/UFRJ.

Pesquisador adjunto do IBICT

Lidiane dos Santos Carvalho - carvalho.Idn@gmail.com Mestre em Ciência da Informação pela UFSC
\end{abstract}

\begin{abstract}
Resumo
Neste artigo discutem-se as relações entre informação, comunicação e inovação tecnológica na Fundação CERTI (Centros de Referência em Tecnologias Inovadoras), vinculada à Universidade Federal de Santa Catarina. Faz-se uso de conceitos e de abordagens críticas da Ciência da Informação. Apresenta-se a discussão da relação entre informação e inovação. Discute-se, a partir da Teoria do Agir Comunicativo de Habermas, a colaboração nas organizações como condição para dinâmicas complexas que induzam, produzam e incorporem inovações. Discutem-se os pressupostos de uma gestão da inovação tecnológica. Os métodos de pesquisa usados incluem, além da pesquisa bibliográfica, o estudo na Fundação CERTI, com recuperação de documentos e entrevistas com questionário estruturado. Os resultados evidenciam a relevância da informação e da comunicação para colaboração e inovação. Conclui-se que a adequada gestão da informação e da comunicação pode contribuir para eficácia e inovação em organizações complexas, particularmente em institutos de pesquisa cientifica e tecnológica.
\end{abstract}

\section{Palavras-chave}

Gestão da informação. Comunicação. Inovação.

\section{INTRODUÇÃO}

Neste artigo discutem-se as relações entre informação, comunicação e inovação em uma organização complexa a partir de estudo de caso destas relações na Fundação CERTI - Centros de Referência em Tecnologias Inovadoras, vinculado a Universidade Federal de Santa Catarina.

O marco teórico desta pesquisa parte da reorganização do capitalismo pós-industrial, no qual emerge a relevância do trabalho imaterial e das formas colaborativas de produção. Na socie- 
dade da informação as tecnologias e informação e comunicação contribuem para novas formas de organização social em rede. Faz-se então a discussão das relações entre informação e inovação.

Apresentam-se visões distintas da informação: um operador funcional de sistemas sociais ou uma dinâmica complexa. O conceito de informação usado interfere profundamente na forma como se representa e analisa a sua organização e gestão. São discutidos conceitos de inovação e dos processos de inovação para destacar neles o papel da informação, como elemento constitutivo e dinamizador.

Cabe mencionar o conceito funcional de inovação tecnológica: introdução de produtos ou processos tecnologicamente novos e melhorias significativas que tenham sido implantadas em produtos e processos existentes. Considera-se inovação tecnológica de produto ou processo aquela que tenha sido implementada e introduzida no mercado - inovação de produto - ou utilizada no processo de produção - inovação de processo (OCDE, 2004).

Machado, Lehmann e Araujo (2008) caracterizam inovação como: a capacidade de uma organização de articular e mobilizar recursos (humanos, financeiros, materiais, etc.), para captar oportunidades e neutralizar ameaças (operacionais, mercadológicas, etc.); o processo de transformação de idéias (inovação) em soluções que atendam às necessidades existentes ou latentes; e o resultado de uma atividade criativa que resulta na forma de produtos, processos e sistemas, novos ou modificados.

Faz-se então da discussão da comunicação nas organizações. Parte-se da visão que os sistemas de informação são processos de comunicação dentro das organizações. A partir de então se discute a Teoria do Agir Comunicativo de Jürgen Habermas, especialmente sua noção de uma ética da discussão. Discute-se o processo de comunicação nas organizações como condição para que a dinâmica interna produza e incorpore inovações.

São apresentados os resultados da investigação sobre informação, comunicação e inovação tecnológica na Fundação CERTI, instituição de pesquisa e desenvolvimento tecnológico vinculado a Universidade Federal de Santa Catarina com foco na inovação em negócios, produtos e serviços. Esta investigação combina observação participante, busca de documentos e entrevistas estruturadas.

A apresentação desta organização parte da sua caracterização da Fundação CERTI como organização complexa, incluindo a sua estrutura organizacional. Descrevem-se os processos de inovação, destacando-se os elementos que a organização considera chave para os mesmos: gestão, cooperação e financiamento. São descritos os resultados de entrevistas estruturadas com doze dirigentes da organização. A partir daí são enunciadas diretrizes para a gestão da informação para inovação em organizações complexas. 


\section{INFORMAÇÃO E INOVAÇÃO}

Ao responder a indagação "do que falamos quando se fala de informação", González de Gomez (2000) afirma tratar-se de um termo flutuante que, tal como o de democracia, produz diferentes efeitos de sentido em diferentes contextos. Informação, como construção e sintoma da sociedade contemporânea, designa algo que se desdobra em vários planos de realização - todos eles transcendidos por valores semânticos e quadros normativos, da ordem do ideacional, e ancorados no solo de sua inscrição ou manifestação, da ordem do visível e do temporal.

González de Gomez (2008) observa que a informação tem para Habermas dupla ancoragem - socio-cognitiva e instrumental-estratégica. Por um lado, a informação está ancorada naquela temporalidade que atrela corpo e cultura numa configuração diferenciada e permite a abertura de múltiplas perspectivas sobre o mundo. Associada a algumas das plurais possibilidades heurísticas das ações - cotidianas e especializadas - a informação designa uma diferença que se instala nas experiências de confronto entre nossas expectativas prévias e do que acontece em nossas relações atuais com o mundo. Por outro lado, a informação, enquanto codificada, reconstitui-se através dos meios, nas zonas de trocas e negociação entre os sistemas e os mundos da vida - mediação porém constituída numa relação histórica e não "lógica”, plausível, então, de ambivalências e de transformações.

A informação designa uma instância de constante reabertura das relações entre o mundo da vida e o mundo. A informação é considerada neste caso como constitutiva dos processos de objetivação nos contextos da experiência e da ação. Nessas dinâmicas da informação acontece a manifestação da alteridade, do que surpreende, e como tal, ela faz parte das condições da aprendizagem e dos desafios à imaginação lingüística (GONZÁLEZ DE GOMEZ, 2008).

A informação, enquanto codificada e imersa nos meios, opera no dominio dos sistemas da administração, da economia e do mercado -, em exercícios funcionais-instrumentais, e nas zonas de intermediação entre o sistema e os mundos da vida. A informação, mediatizada, ficaria associada ao problema da constituição do vínculo social, nas sociedades contemporâneas: nas situações em que a integração social, comunicativa, é substituída pela integração estabelecida por meios (GONZÁLEZ DE GOMEZ, 2008).

Melhado (2005) destaca que a Ciência da Informação, ao estudar propriedades da informação e processos de sua construção, comunicação e uso, quer compreender os problemas sociais advindos da necessidade de informações, do surgimento da indústria da informação e do advento de novas tecnologias que estabelecem um novo paradigma de manipulação associado à informação. O tema inovação tecnológica é objeto dessa nova ciência, por representar a criação e o uso de ferramentas de informação.

A inovação é, de acordo com o Manual de Oslo, um processo complexo e a gama de atividades exigida para a inovação em uma organização pode variar consideravelmente. $\mathrm{O}$ desenvol- 
vimento dentro da própria organização de um produto radicalmente diferente e sofisticado para o mercado de massa pode envolver muitas etapas mais do que a introdução de processo aprimorado resultante de tecnologia incorporada em uma máquina pré-programada adquirida para tal fim (OCDE, 2004).

Schumpeter (1961) afirma que são cinco os tipos básicos de inovação: 1) desenvolvimento de um novo produto, ou de uma nova tecnologia de um bem já existente; 2) desenvolvimento de um método de produção, ou de uma nova logística comercial; 3)desenvolvimento de um novo mercado; 4) desenvolvimento de novas fontes de suprimento das matérias-primas ou produtos semi-industrializados; 5) desenvolvimento de uma nova organização industrial, como a criação ou a fragmentação de uma posição de monopólio.

Dosi (1982) destaca que a inovação possui quatro propriedades fundamentais: (i) incerteza; (ii) crescente dependência das novas oportunidades tecnológicas no conhecimento científico; (iii) crescente formalização das atividades de pesquisa e desenvolvimento e, (iv) learn-bydoing (aprender fazendo). Pode-se analisar que nas inovações ocorrem incertezas quando existem problemas técnico-econômicos, onde as soluções são desconhecidas e deve-se atuar para diminuir estes problemas.

Dosi (1984) destaca três características econômicas relevantes para a análise da inovação tecnológica: a) grau de oportunidade tecnológica - oportunidade de introdução de avanços tecnológicos rentáveis; b) cumulatividade nas capacidades tecnológicas - inerente aos padrões de inovações e à capacidade de inovar das empresas; e c) apropriação privada das vantagens advindas da inovação - retorno econômico do progresso técnico. As três características condicionam fortemente o processo de inovação e são utilizadas pelas empresas como fatores para proteger eventuais vantagens competitivas e erguer barreiras aos concorrentes.

Nyström (1993) argumenta que existem três principais variáveis ligadas ao sucesso dos processos de inovação:

- Abertura e flexibilidade organizacional: a flexibilidade e a abertura podem ser criadas tanto internamente na organização quanto na sua relação com o ambiente. Com relação à organização interna, a flexibilidade pode ser desenvolvida por meio de projetos de grupos flexíveis;

- Orientação tecnológica: muitas vezes no processo de inovação as empresas devem ter uma orientação tecnológica voltada ao produto; e

- Uso da tecnologia: com uma orientação tecnológica no processo inovativo as empresas utilizam novas tecnologias para aperfeiçoar suas cadeias produtivas e, conseqüentemente, seus produtos.

Lemos (1999) observa que uma organização não inova sozinha, pois as fontes de informações, conhecimentos e inovação podem ser localizar tanto dentro, quanto fora dela. O processo 
de inovação é, portanto, um processo interativo, realizado com a contribuição de variados agentes econômicos e sociais que possuem diferentes tipos de informações e conhecimentos. A composição de várias fontes de informações e conhecimentos é considerada uma importante maneira das organizações se capacitarem para produzir inovações e enfrentar mudanças, tendo em vista que a solução da maioria dos problemas tecnológicos implica em uso de conhecimentos de vários tipos.

O processo de produção de conhecimentos e de inovação implica em desenvolvimento de capacidades cientificas, tecnológicas e organizações e esforços de aprendizado com a experiência própria, no processo de produção, comercialização e uso; na busca incessante de novas soluções técnicas nas unidades de pesquisa e desenvolvimento; e na interação com fontes externas, como fornecedores de insumos, consultores e universidades (LEMOS, 1999).

\section{A COMUNICAÇÃO NAS ORGANIZAÇÕES}

Luhmann (1990) afirma que a capacidade humana não dá conta de apreensão de todos os possíveis acontecimentos e todas as circunstâncias no mundo. Ela é, constantemente, exigida demais. Entre a extrema complexidade do mundo e a capacidade de entendimento humana existe uma lacuna. Neste ponto os sistemas sociais assumem a sua função, assumindo a tarefa de redução de complexidade. Os sistemas sociais intervêm entre a extrema complexidade do mundo e a limitada capacidade do homem em trabalhar a complexidade.

Os sistemas sociais reduzem a complexidade do mundo excluindo possibilidades e selecionando outras $\mathrm{O}$ sistema define-se por sua diferença com relação ao entorno. $\mathrm{O}$ sistema que contém em si sua diferença é um sistema auto-referente e operacionalmente fechado e que se constitui como tal, reduzindo a complexidade do entorno. Os sistemas sociais constroem sua própria complexidade, fechando-se operacionalmente em relação ao entorno, e produzindo seus próprios elementos (LUHMANN, 1991).

Kunzler (2004) afirma que toda e qualquer comunicação que possa existir é interna ao sistema social e, em última análise, à sociedade que é formada por todos os sistemas sociais. Entre o sistema e o ambiente não há comunicação. O sistema social operacionalmente fechado não recebe informação do ambiente, mas devido a esse fechamento pode abrir-se ao ambiente para observá-lo sem por em risco sua própria identidade. No ambiente está tudo que não é comunicação, mas que pode servir de tema para a comunicação interna do sistema.

O sistema é levado a re-elaborar suas estruturas a partir do estímulo provocado pela comunicação. O sistema está estruturalmente pronto para receber aquilo que espera como provável. Entretanto, quando o provável não acontece, ou seja, quando surge uma diferença, surge, então, uma informação que faz com que o sistema mude suas estruturas. Pode-se afirmar que a informação é uma diferença. E mais: a informação é uma diferença que provoca diferenças, na medida 
em que o sistema modifica suas estruturas, tornando-se diferente, para receber a informação (KUNZLER, 2004).

Lyytinien (1987) oferece um enfoque interessante, ao considerar um sistema de informação como instituição comunicativa, afirmando que se assemelha a "um meio de comunicação de massa para um grupo local". A criação de cada sistema de informação daria origem ou atualização a uma instituição de comunicação que intervém no meio social por meio de atividades de modelagem informacional: "um sistema de informação é um instrumento lingüístico de comunicação".

Lyytinien (1987) diz que conceber um sistema de informação requer compreender o duplo arcabouço de sua constituição: a forma de vida que visa a sustentar ou a modificar pela regulação dos fluxos de informação; e a inclusão na organização que define a funcionalidade como instituição comunicacional de caráter local. A comunicação através do sistema de informação cria, controla e dá sustentação às interações sociais num contexto organizacional. O caráter específico de um sistema de informação como meio de comunicação deriva da natureza formal de sua linguagem e dos modos preestabelecidos de seu uso.

González de Gomez (2004) comenta que os estudos de Lyytinien, que introduzem conceitos da Teoria do Agir Comunicativo de Habermas ao domínio da concepção de sistemas, além de colocar em relevo o caráter comunicacional do sistema de informação, introduzem elementos críticos nas visões racionalistas de transparência do sistema. No contexto das redes digitais interativas é mais difícil ainda manter as premissas lineares do racionalismo sistêmico: as condições econômicas, políticas e sociais desdobram-se em complexas infra-estruturas e dispositivos tecnológicos, produzem transformações comunicativas e informacionais não intencionalizadas nem sempre visíveis para os agentes imediatos da enunciação ou destinação.

González de Gomez (2008) afirma que a potência da linguagem sobre a qual se sustenta a racionalidade comunicativa é exercida em três direções: como representação, pela remissiva do enunciado a um dominio de referência; como comunicação, enquanto construção em comum de significados e instauração do compromisso pragmático entre os participantes da ação comunicativa; como expressão da subjetividade, por colocar o ator social frente aos outros, parceiros, públicos ou oponentes, e dando ocasião a atitude reflexiva e a formação de identidades, que são condições da autonomia e responsabilidade de sujeitos imputáveis.

Habermas (1989) chama comunicativas as interações nas quais as pessoas envolvidas se põem de acordo para coordenarem seus planos de ação, o acordo alcançado em cada caso medindo-se pelo reconhecimento intersubjetivo das pretensões de validez. No caso de processos de entendimento lingüístico, os atores erguem pretensões de validez com seus atos de fala, ao se entenderem uns com os outros sobre algo. No agir comunicativo um é motivado racionalmente pelo outro para uma ação de adesão. 
No agir comunicativo os atores tratam de harmonizar seus planos de ação e de perseguir suas metas sob a condição de um acordo existente ou a se negociar sobre a situação e as conseqüências esperadas. Em ambos os casos a estrutura teleológica da ação é pressuposta na medida em que se atribui aos atores a capacidade de agir em vista de um objetivo e o interesse em executarem seus planos de ação. O agir estratégico é composto por estruturas do agir imediatamente orientado para o sucesso (HABERMAS, 1989).

Quando se tem presente a função coordenadora das ações que as pretensões de validez normativas desempenham na prática comunicativa cotidiana, percebe-se por que os problemas que devem ser resolvidos em argumentações não podem ser superados de modo mono-lógico, mas exigem um esforço de cooperação. Ao entrarem numa argumentação os participantes prosseguem o agir comunicativo em uma atitude reflexiva, para restaurar um entendimento perturbado. As argumentações servem para dirimir os conflitos de ação (HABERMAS, 1989).

A ética da discussão desenvolvida por Habermas (1989) dá orientação de procedimento rico em pressupostos que deve garantir a imparcialidade da formação de juízo. O discurso prático é um processo, não para a produção de normas justificadas, mas para o exame da validade de normas consideradas hipoteticamente. É só com este procedimento que a ética da discussão se diferencia de outras éticas cognitivistas, universalistas e formalistas. Todos os conteúdos, mesmo os concernentes a normas de ação, não importa quão fundamentais estas sejam, têm de ser colocados na dependência de discursos reais.

A ética do discurso vem ao encontro de uma concepção construtivista da aprendizagem, na medida em que compreende a formação discursiva da vontade (assim como a argumentação em geral) como uma forma de reflexão do agir comunicativo e na medida em que exige, para a passagem do agir para o discurso, uma mudança de atitude. Na argumentação as pretensões de validade são expressamente tematizadas e problematizadas (HABERMAS, 1989).

A discussão prática acontece, de acordo com Habermas (1989), quando o modo de agir carece de fundamentação de natureza coletiva e os membros da organização têm que chegar a uma decisão comum sobre suas ações, e têm que tentar convencer-se mutuamente de que é interessante para cada um que todos ajam assim. Neste processo cada um indica ao outro as razões por que ele pode querer que um modo de ação seja tornado socialmente obrigatório. Cada pessoa tem de se convencer de que a norma proposta é igualmente boa para todos. A discussão pode criar argumentos que legitimem a decisão de orientações para a ação coletiva e acordos práticos.

Habermas (1989) observa que são necessários dispositivos institucionais a fim de neutralizar as limitações inevitáveis e as influências internas e externas evitáveis, de tal sorte que as condições idealizadas possam ser preenchidas pelo menos numa aproximação suficiente. Essas necessidades de institucionalização de discursos não contradizem de modo algum o conteúdo parcialmente contra-factual das suas pressuposições. 


\section{INFORMAÇÃO, COMUNICAÇÃO E INOVAÇÃO NA FUNDAÇÃO CERTI}

O estudo das relações entre informação, comunicação e inovação é desenvolvido na Fundação CERTI - Centros de Referência em Tecnologias Inovadoras, que é uma instituição independente de pesquisa e desenvolvimento tecnológico com foco na inovação em negócios, produtos e serviços. A CERTI é referência em âmbito nacional pelo desenvolvimento de projetos inovadores que envolvem soluções de convergência digital, como a urna eletrônica brasileira, os terminais de automação bancária e terminais públicos de acesso à Internet.

Criada em 1984, por iniciativa de algumas empresas brasileiras, da Universidade Federal de Santa Catarina e dos Governos Federal e Estadual, a Fundação CERTI surge dentro do Labmetro - Laboratório de Metrologia do Departamento de Engenharia Mecânica da UFSC - Universidade Federal de Santa Catarina, e desde 1990 funciona em prédio próprio no campus da UFSC.

Ao longo dos seus vinte e dois anos a Fundação CERTI tem focado suas ações na cadeia produtiva da tecnologia da informação, sistemas mecatrônicos, metrologia e garantia da qualidade, com uma atuação integrada de seus Centros de Referência, dos seus Laboratórios e de seus Institutos. Em função de demandas empresariais, a Fundação estabeleceu em Manaus e em Brasília institutos tecnológicos que atuam em áreas semelhantes e complementares, respectivamente, o Instituto CERTI Manaus e o Instituto Sapientia.

No campo da pesquisa e desenvolvimento, a CERTI destaca-se ao longo dos anos nos campos da metrologia, no desenvolvimento e customização de projetos que envolvem a prototipagem e montagem de placas de circuitos eletrônicos com o diferencial de produção em séries pequenas, na Meca optoeletrônica, em sistema da qualidade e, mais recentemente, na área de gestão empresarial.

Mais de seiscentas empresas e instituições de todo o Brasil beneficiam-se, anualmente, dos serviços tecnológicos, dos projetos de melhoria de processos, dos desenvolvimentos de produtos inovadores e dos empreendimentos tecnológicos desenvolvidos pelos Centros da Fundação CERTI.

O trabalho da Fundação CERTI é realizado por intermédio de sete Centros, sendo cinco deles denominados CRIT - Centro de Referência em Tecnologias Inovadoras, com competências tecnológicas específicas e equipes de colaboradores próprios, com formação no país e no exterior.

Os cinco CRIT atuais são: CME - CRIT em Dispositivos Meca-Opto-Eletrônicos; CMI CRIT em Soluções de Metrologia e Instrumentação; CPC - CRIT em Sistemas Produtivos Cooperativos; CAI - CRIT em Ambientes de Inovação; CCD - CRIT em Soluções de Convergência Digital. Os outros dois Centros da CERTI são: CIENCIA - Centro Incubador de Empreendimentos, Novos Conhecimentos e Idéias Avançadas; CELTA - Centro Empresarial para Laboração de Tecnologias Avançadas. 
O conceito de inovação na Fundação CERTI considera que ela é processo que pode acontecer em dois momentos: com a inovação de um produto que ocorre através de um processo organizacional, ou da melhoria tecnológica que inova o processo produtivo. O processo de inovação tecnológica de produtos de sucesso no mercado parte idéias e oportunidades. Este processo requer a definição de estruturas organizacionais que possibilitem uma melhor adaptação da empresa aos mercados e o posicionamento que se pretende atingir face aos mesmos. Ver Figura 1.

O conceito de inovação usado na Fundação CERTI orienta suas ações para assegurar três condições: ter a gestão interna para promover a inovação; manter cooperação e parceria com outras empresas e instituições de pesquisa e desenvolvimento; e, por último, saber fazer uso de oportunidades de incentivos e financiamentos (FUNDAÇÃO CERTI, 2009).

O processo de inovação é constituído de uma seqüência ampla de operações, que vão da pesquisa ao marketing, e sustentado pela gestão, cooperação e financiamento, tendo o conhecimento e a tecnologia como elementos fundamentais para o êxito do processo. O êxito da inovação depende de investimentos, logo, a questão financiamento e o conhecimento dos mecanismos para sua obtenção são por vezes fundamentais para sua viabilização.

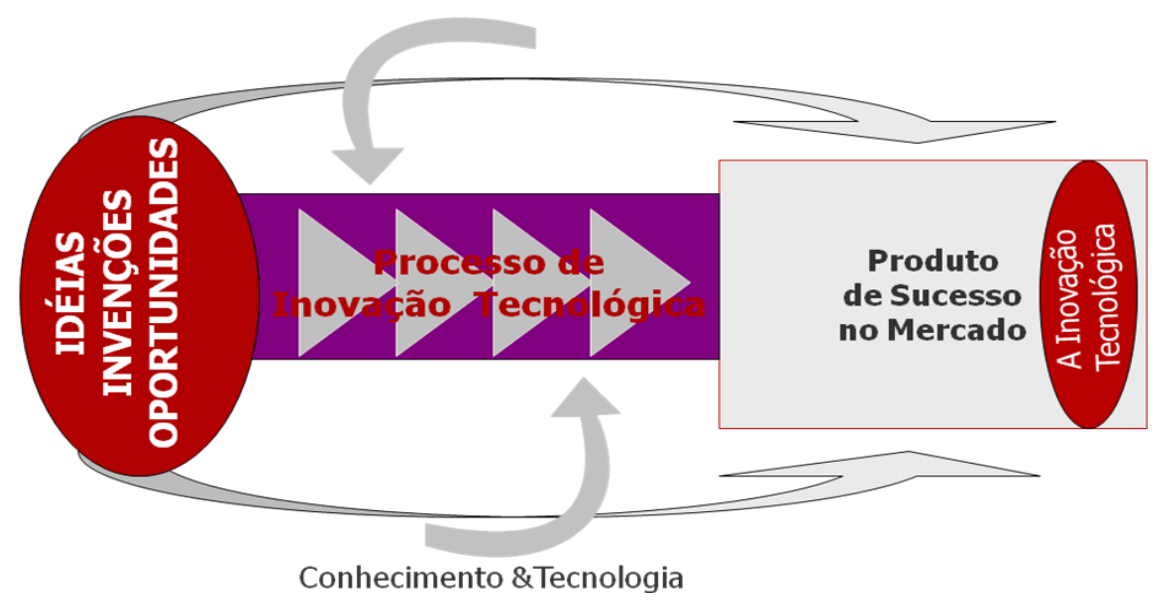

Figura 1 - O processo de inovação tecnológica de produtos na Fundação CERTI.

Fonte: Fundação CERTI, 2009.

É muito difícil a organização desenvolver a multiplicidade de operações requeridas de forma autônoma. O conhecimento, as tecnologias e as operações associadas podem ser fortalecidos ou supridos pela cooperação com Instituições de Ciência, Tecnologia e Inovação, ou mesmo por outras empresas. Finalmente, para que o processo de inovação seja eficaz e efetivo, é fundamental uma boa gestão, de forma a diminuir riscos, aperfeiçoar o uso de recursos e aproveitar as oportunidades de parcerias e financiamentos existentes no Estado, no País e até no exterior (INOVA, 2009). 


\section{A REALIDADE ORGANIZACIONAL DA FUNDAÇÃO CERTI}

O questionário utilizado nas entrevistas com doze dirigentes da Fundação CERTI para caracterização da realidade organizacional inclui vinte e seis assertivas, acompanhada cada uma delas de dois cenários extremos.

As vinte e seis assertivas são focadas em aspectos pertinentes para a investigação das relações entre informação, comunicação e inovação. Cada assertiva refere-se a uma questão relevante dentro da organização e deve ser avaliada usando a escala Likert (notas de 1 a 5). As assertivas que recebem nota baixa caracterizam uma deficiência, enquanto que as notas altas apontam para aspectos positivos na organização. A escala de Likert baseia-se na premissa de que a atitude geral se remete às crenças sobre o objeto da atitude, à força que mantém essas crenças e aos valores ligados ao objeto.

São apresentados dois cenários explicativos para cada assertiva, sendo um péssimo (cenário 1) e o outro ótimo (cenário 5). Caso a situação da organização se enquadre mais no cenário péssimo, a nota deverá ser mais próxima de 1. Se a organização apresenta mais características do cenário ótimo, a nota deverá ser mais próxima de 5 . O cenário com o maior grau de incidência das respostas corresponde a moda. Os questionários usados nas entrevistas não são individualizados, optando-se por uma avaliação de resultados do coletivo de dirigentes.

\begin{tabular}{|c|c|c|c|c|c|c|c|}
\hline $\begin{array}{l}\text { CENÁRIO PARA } \\
\text { ANÁLISE }\end{array}$ & CENÁRIO 1 & CENÁRIO 5 & 1 & 2 & 3 & 4 & 5 \\
\hline $\begin{array}{c}\text { A organização coleta } \\
\text { informações do mercado, } \\
\text { tal que sua programação } \\
\text { seja realizada com } \\
\text { segurança e flexibilidade. }\end{array}$ & $\begin{array}{l}\text { Não há canais onde as } \\
\text { informações do mercado } \\
\text { são captadas para que } \\
\text { ocorram mudanças no } \\
\text { sistema produtivo. }\end{array}$ & $\begin{array}{c}\text { Há canais onde as } \\
\text { informações do mercado } \\
\text { são captadas para que } \\
\text { sejam geradas } \\
\text { mudanças no sistema } \\
\text { produtivo. }\end{array}$ & & 1 & 7 & 4 & \\
\hline $\begin{array}{l}\text { O desenvolvimento de } \\
\text { novos produtos da } \\
\text { organização utiliza } \\
\text { informações dos clientes. }\end{array}$ & $\begin{array}{c}\text { Não há participação dos } \\
\text { clientes no } \\
\text { desenvolvimento dos } \\
\text { novos produtos. }\end{array}$ & $\begin{array}{c}\text { Sempre há participação } \\
\text { dos clientes no } \\
\text { desenvolvimento dos } \\
\text { novos produtos. }\end{array}$ & & & 1 & 1 & 1 \\
\hline $\begin{array}{l}\text { As medidas de satisfação } \\
\text { dos clientes são } \\
\text { consideradas no controle. }\end{array}$ & $\begin{array}{l}\text { Não há consideração do } \\
\text { grau de satisfação dos } \\
\text { clientes como fator de } \\
\text { desempenho } \\
\text { operacional. }\end{array}$ & $\begin{array}{l}\text { Há consideração do grau } \\
\text { de satisfação dos } \\
\text { clientes como fator de } \\
\text { desempenho } \\
\text { operacional. }\end{array}$ & & 2 & 5 & 5 & \\
\hline
\end{tabular}

Quadro 1: Coleta e uso de informações dos clientes e do mercado.

A organização tem um nível apenas regular na coleta de informações do mercado, tal que sua programação seja realizada com segurança e flexibilidade. A organização faz bom uso das informações dos clientes no desenvolvimento de novos produtos e possui boa adaptação às necessidades dos clientes. Entretanto, possui um nível regular de uso das medidas de satisfação dos clientes nos seus controles. 


\begin{tabular}{|c|c|c|c|c|c|c|c|c|}
\hline $\begin{array}{l}\text { CENÁRIO PARA } \\
\text { ANÁLISE }\end{array}$ & CENÁRIO 1 & CENÁRIO 5 & 1 & 2 & 3 & 4 & 5 & B \\
\hline $\begin{array}{l}\text { A cultura da mudança e } \\
\text { da inovação está } \\
\text { explícita na identidade } \\
\text { e consolidada em todos } \\
\text { os setores da } \\
\text { organização. }\end{array}$ & $\begin{array}{l}\text { O desenvolvimento de } \\
\text { novos produtos está } \\
\text { imerso na cultura dos } \\
\text { funcionários. }\end{array}$ & $\begin{array}{l}\text { O desenvolvimento de } \\
\text { novos produtos é } \\
\text { intrínseco na cultura dos } \\
\text { funcionários. }\end{array}$ & & 1 & & 5 & 5 & 1 \\
\hline $\begin{array}{l}\text { Os projetos produtivos } \\
\text { têm em conta variáveis } \\
\text { como: capacidade, } \\
\text { habilidade e nível de } \\
\text { instrução dos } \\
\text { funcionários. }\end{array}$ & $\begin{array}{c}\text { A capacidade, a } \\
\text { habilidade e o nível de } \\
\text { instrução dos } \\
\text { funcionários não são } \\
\text { considerados nos } \\
\text { projetos produtivos, } \\
\text { provocando aumento nos } \\
\text { tempos de ciclo da } \\
\text { produção. }\end{array}$ & $\begin{array}{c}\text { A capacidade, a } \\
\text { habilidade e o nível de } \\
\text { instrução dos } \\
\text { funcionários são } \\
\text { considerados nos } \\
\text { projetos produtivos, } \\
\text { ajudando na redução dos } \\
\text { tempos de ciclo da } \\
\text { produção. }\end{array}$ & & 1 & 2 & 4 & 4 & 1 \\
\hline $\begin{array}{l}\text { Há uma prática de } \\
\text { desenvolver projeto de } \\
\text { produto envolvendo } \\
\text { setores variados. }\end{array}$ & $\begin{array}{l}\text { Os projetos são tarefas } \\
\text { exclusivas da área } \\
\text { específica; os resultados } \\
\text { são apenas } \\
\text { comunicados. }\end{array}$ & $\begin{array}{c}\text { Há um amplo } \\
\text { envolvimento de grande } \\
\text { número de áreas; } \\
\text { entende-se que uma } \\
\text { maior participação } \\
\text { melhora o projeto e } \\
\text { minimiza erros. }\end{array}$ & & 1 & 5 & 1 & 5 & \\
\hline
\end{tabular}

Quadro 2: Cultura de colaboração para inovação.

A Fundação CERTI tem uma cultura de mudança e de inovação explicita na sua identidade, consolidada em todos os setores. A organização tem muito bom nível de observação das variáveis referentes aos seus colaboradores (capacidade, habilidade e nível de instrução) nos projetos produtivos. Contudo, a organização tem bem demarcados dois cenários sobre o envolvimento de vários setores no desenvolvimento de projetos de produtos: um regular e outro ótimo.

\begin{tabular}{|c|c|c|c|c|c|c|c|}
\hline $\begin{array}{l}\text { CENÁRIO PARA } \\
\text { ANÁLISE }\end{array}$ & CENÁRIO 1 & CENÁRIO 5 & 1 & 2 & 3 & 4 & 5 \\
\hline $\begin{array}{l}\text { A competitividade da } \\
\text { organização se baseia na } \\
\text { qualidade dos seus } \\
\text { produtos. }\end{array}$ & $\begin{array}{c}\text { A boa qualidade NÃO } \\
\text { interfere na } \\
\text { competitividade }\end{array}$ & $\begin{array}{c}\text { A boa qualidade interfere } \\
\text { na competitividade da } \\
\text { empresa }\end{array}$ & & & 2 & 3 & 7 \\
\hline $\begin{array}{c}\text { A organização tem a } \\
\text { preocupação de investir } \\
\text { na qualidade objetivando } \\
\text { melhorar sua } \\
\text { competitividade. }\end{array}$ & $\begin{array}{c}\text { Os investimentos } \\
\text { realizados na } \\
\text { organização NÃO } \\
\text { contemplam a área da } \\
\text { qualidade }\end{array}$ & $\begin{array}{c}\text { Os investimentos } \\
\text { realizados na } \\
\text { organização contemplam } \\
\text { a qualidade, que possui } \\
\text { um orçamento fixo a ser } \\
\text { utilizado para o seu } \\
\text { aprimoramento. }\end{array}$ & 1 & 2 & 6 & 2 & 1 \\
\hline
\end{tabular}

Quadro 3: Qualidade na produção. 
A Fundação CERTI baseia sua competitividade na qualidade dos produtos e tem conseguido uma boa comunicação desta qualidade ao consumidor final. Por outro lado, a organização tem um nível regular de investimentos na qualidade visando melhorar sua competitividade. Além disto, há uma grande heterogeneidade na visão interna sobre este nível de investimentos.

\begin{tabular}{|c|c|c|c|c|c|c|c|c|}
\hline $\begin{array}{l}\text { CENÁRIO PARA } \\
\text { ANÁLISE }\end{array}$ & CENÁRIO 1 & CENÁRIO 5 & 1 & 2 & 3 & 4 & 5 & B \\
\hline $\begin{array}{l}\text { Os equipamentos e as } \\
\text { tecnologias têm } \\
\text { permitido arranjos } \\
\text { flexíveis, como as } \\
\text { células de produção. }\end{array}$ & $\begin{array}{l}\text { O layout é inflexível e } \\
\text { pouco econômico; } \\
\text { deveria ser diferente. }\end{array}$ & $\begin{array}{c}\text { Há flexibilidade de tipo e } \\
\text { quantidade de produção; } \\
\text { o layout não deverá } \\
\text { mudar. }\end{array}$ & & 1 & 3 & 6 & 1 & 1 \\
\hline $\begin{array}{l}\text { Percebe-se que o } \\
\text { incremento em } \\
\text { equipamentos e novas } \\
\text { tecnologias têm } \\
\text { influência positiva na } \\
\text { qualidade e seus } \\
\text { resultados alcançados. }\end{array}$ & $\begin{array}{c}\text { A falta de equipamentos } \\
\text { de nova tecnologia não } \\
\text { interfere na qualidade } \\
\text { dos produtos }\end{array}$ & $\begin{array}{l}\text { Novos equipamentos e } \\
\text { tecnologia contribuem } \\
\text { para um melhor } \\
\text { resultado, visando } \\
\text { melhor qualidade. }\end{array}$ & & 1 & 3 & 5 & 3 & \\
\hline $\begin{array}{l}\text { A tecnologia de } \\
\text { informação utilizada } \\
\text { proporciona um controle } \\
\text { eficaz dos tempos de } \\
\text { ciclo da produção. }\end{array}$ & $\begin{array}{l}\text { A organização não } \\
\text { utiliza uma tecnologia de } \\
\text { informação propícia para } \\
\text { fazer um controle do } \\
\text { ciclo produtivo, } \\
\text { prejudicando os tempos } \\
\text { na produção. }\end{array}$ & $\begin{array}{l}\text { A utilização de um bom } \\
\text { sistema de informação } \\
\text { no controle da produção } \\
\text { promove a redução dos } \\
\text { tempos de ciclo. }\end{array}$ & & 3 & 6 & 1 & 2 & \\
\hline
\end{tabular}

Quadro 4: O uso de tecnologias no processo produtivo.

A organização tem bons equipamentos e tecnologias, que tem permitido arranjos flexíveis de produção. O incremento em equipamentos e novas tecnologias têm boa influência na qualidade e nos resultados obtidos. Apesar disto, a tecnologia de informação e comunicação utilizada proporciona condições regulares para controle dos tempos de produção.

\begin{tabular}{|c|c|c|c|c|c|c|c|c|}
\hline $\begin{array}{l}\text { CENÁRIO PARA } \\
\text { ANÁLISE }\end{array}$ & CENÁRIO 1 & CENÁRIO 5 & 1 & 2 & 3 & 4 & 5 & B \\
\hline $\begin{array}{l}\text { O planejamento faz com } \\
\text { que os procedimentos } \\
\text { de elaboração e } \\
\text { desenvolvimento de } \\
\text { produtos sejam } \\
\text { documentados. }\end{array}$ & $\begin{array}{c}\text { Não existem } \\
\text { documentação sobre } \\
\text { procedimentos de } \\
\text { elaboração e } \\
\text { desenvolvimento de } \\
\text { produtos }\end{array}$ & $\begin{array}{c}\text { Existe documentação } \\
\text { sobre procedimentos de } \\
\text { elaboração e } \\
\text { desenvolvimento de } \\
\text { produtos }\end{array}$ & & 1 & 3 & 6 & 1 & 1 \\
\hline $\begin{array}{l}\text { O desenvolvimento de } \\
\text { novos produtos está } \\
\text { regulamentado por } \\
\text { normas de qualidade. }\end{array}$ & $\begin{array}{l}\text { Não existem padrões de } \\
\text { qualidade para o } \\
\text { desenvolvimento de } \\
\text { novos produtos. }\end{array}$ & $\begin{array}{l}\text { A organização tem e } \\
\text { segue padrões de } \\
\text { qualidade para o } \\
\text { desenvolvimento de } \\
\text { novos produtos. }\end{array}$ & & & 4 & 5 & 2 & 1 \\
\hline
\end{tabular}




\begin{tabular}{|c|c|c|c|c|c|}
\hline $\begin{array}{l}\text { Os níveis de autonomia, } \\
\text { auto-organização e } \\
\text { cooperação no } \\
\text { desempenho } \\
\text { operacional são } \\
\text { registrados quando do } \\
\text { desenvolvimento de }\end{array}$ & $\begin{array}{l}\text { Não há controles quanto } \\
\text { ao desempenho } \\
\text { operacional quando são } \\
\text { incorporados novos } \\
\text { produtos. }\end{array}$ & $\begin{array}{l}\text { Há controles quanto ao } \\
\text { desempenho } \\
\text { operacional quando são } \\
\text { incorporados novos } \\
\text { produtos. }\end{array}$ & 1 & 8 & 3 \\
\hline $\begin{array}{l}\text { Os controles refletem e } \\
\text { permitem a capacidade } \\
\text { de auto-organização das } \\
\text { equipes produtivas. }\end{array}$ & $\begin{array}{c}\text { Não existem controles } \\
\text { da produção que } \\
\text { proporcionem a } \\
\text { capacidade de auto- } \\
\text { organização das equipes } \\
\text { produtivas, prejudicando } \\
\text { os tempos de ciclo da } \\
\text { produção }\end{array}$ & $\begin{array}{l}\text { Os controles da } \\
\text { produção proporcionam } \\
\text { a capacidade de auto- } \\
\text { organização das equipes } \\
\text { produtivas, melhorando } \\
\text { os tempos de ciclo da } \\
\text { produção }\end{array}$ & 2 & 7 & 3 \\
\hline
\end{tabular}

Quadro 5: O desenvolvimento de produtos.

O desenvolvimento de novos produtos possui boa regulamentação por normas de qualidade. A organização possui um nível bom na documentação dos processos de elaboração e desenvolvimento dos produtos. Entretanto, a organização possui registros apenas regulares quando do desenvolvimento de novos produtos sobre os níveis de autonomia, auto-organização e cooperação no desempenho operacional. Além disto, organização possui um nível regular nos controles da capacidade de auto-organização das equipes produtivas.

\begin{tabular}{|c|c|c|c|c|c|c|c|c|}
\hline $\begin{array}{c}\text { CENÁRIO PARA } \\
\text { ANÁLISE }\end{array}$ & CENÁRIO 1 & CENÁRIO 5 & 1 & 2 & 3 & 4 & 5 & B \\
\hline $\begin{array}{l}\text { A organização investe } \\
\text { continuamente na } \\
\text { capacitação de seus } \\
\text { funcionários para prover } \\
\text { melhoria da qualidade } \\
\text { dos produtos. }\end{array}$ & $\begin{array}{c}\text { Não há investimentos } \\
\text { em treinamento que } \\
\text { infere a qualidade do } \\
\text { produto. }\end{array}$ & $\begin{array}{l}\text { Há investimentos em } \\
\text { treinamento para } \\
\text { garantir qualidade } \\
\text { satisfatória do produto }\end{array}$ & 1 & 4 & 5 & 1 & 1 & \\
\hline $\begin{array}{l}\text { A organização investe } \\
\text { em programas de } \\
\text { incentivo como } \\
\text { premiação aos } \\
\text { funcionários com base } \\
\text { nas contribuições } \\
\text { individuais para o } \\
\text { desempenho coletivo. }\end{array}$ & $\begin{array}{c}\text { A organização não se } \\
\text { comporta de maneira a } \\
\text { fornecer uma } \\
\text { considerável } \\
\text { contribuição com } \\
\text { programas de incentivo }\end{array}$ & $\begin{array}{l}\text { A organização se } \\
\text { comporta de maneira a } \\
\text { fornecer uma } \\
\text { considerável } \\
\text { contribuição com } \\
\text { programas de incentivo }\end{array}$ & 6 & 2 & 3 & 1 & & \\
\hline $\begin{array}{l}\text { Ocorre o envolvimento } \\
\text { dos funcionários para a } \\
\text { implementação de } \\
\text { melhorias no sistema de } \\
\text { produção. }\end{array}$ & $\begin{array}{l}\text { Cada qual cuida do seu } \\
\text { trabalho e não interfere } \\
\text { nem opina no restante. }\end{array}$ & $\begin{array}{l}\text { Ênfase nos trabalhos em } \\
\text { grupo; o clima é } \\
\text { estimulante à } \\
\text { manifestação de idéias. }\end{array}$ & & 1 & 3 & 4 & 3 & 1 \\
\hline
\end{tabular}




\begin{tabular}{|c|c|c|c|c|c|c|c|}
\hline $\begin{array}{c}\text { Os funcionários se } \\
\text { reúnem periodicamente } \\
\text { para gerar idéias } \\
\text { inovadoras para a } \\
\text { melhoria do tempo de } \\
\text { ciclo, buscando } \\
\begin{array}{c}\text { contribuir com } \\
\text { criatividade na redução } \\
\text { de custos da produção. }\end{array}\end{array}$ & $\begin{array}{c}\text { Não há comportamento } \\
\text { positivo dos funcionários } \\
\text { na melhoria da } \\
\text { produção. }\end{array}$ & $\begin{array}{c}\text { O comportamento dos } \\
\text { funcionários favorece } \\
\text { fortemente na melhoria } \\
\text { da produção. }\end{array}$ & 3 & 4 & 4 & 1 & \\
\hline
\end{tabular}

Quadro 6: Trabalho intelectual no processo produtivo.

A organização tem bom envolvimento dos funcionários para a implementação de melhorias no sistema de produção, com nível inferior ao bom na reunião periódica de funcionários para contribuir na redução dos custos de produção. Há grande heterogeneidade na visão interna sobre a reunião dos funcionários para gerar idéias inovadoras. Além disto, a organização possui nível inferior ao regular nos investimentos contínuos na capacitação dos seus colaboradores para melhorar a qualidade dos produtos e não investe em programas de incentivo como premiação aos funcionários com base nas contribuições individuais para o desempenho coletivo.

A Fundação CERTI possui medidas de desempenho que têm boa influência no direcionamento do planejamento. Contudo, a organização possui nível apenas regular nas formas de mensuração do seu desempenho e nível inferior ao regular na monitoria em tempo real das medidas de seu desempenho, que permita ajustes rápidos.

\begin{tabular}{|c|c|c|c|c|c|c|c|}
\hline $\begin{array}{c}\text { CENÁRIO PARA } \\
\text { ANÁLISE }\end{array}$ & CENÁRIO 1 & CENÁRIO 5 & 1 & 2 & 3 & 4 & 5 \\
\hline $\begin{array}{l}\text { Existem formas amplas e } \\
\text { confiáveis de mensuração } \\
\text { do desempenho na } \\
\text { organização. }\end{array}$ & $\begin{array}{l}\text { Não há indicadores de } \\
\text { desempenho na } \\
\text { organização. }\end{array}$ & $\begin{array}{c}\text { Os indicadores de } \\
\text { desempenho são } \\
\text { monitorados em tempo } \\
\text { real e usados na tomada } \\
\text { de decisão. }\end{array}$ & & 3 & 4 & 3 & 1 \\
\hline $\begin{array}{c}\text { As medidas do } \\
\text { desempenho influenciam } \\
\text { diretamente no } \\
\text { direcionamento do } \\
\text { planejamento. }\end{array}$ & $\begin{array}{l}\text { Na elaboração do } \\
\text { planejamento da } \\
\text { produção não são } \\
\text { consideradas as } \\
\text { medidas do } \\
\text { desempenho } \\
\text { operacional. }\end{array}$ & $\begin{array}{c}\text { O planejamento da } \\
\text { produção é realizado de } \\
\text { acordo com as medidas } \\
\text { do desempenho } \\
\text { operacional }\end{array}$ & & 1 & 5 & 6 & \\
\hline $\begin{array}{c}\text { As medidas de } \\
\text { desempenho são } \\
\text { monitoradas em tempo } \\
\text { real (ou tempo muito } \\
\text { curto), permitindo ajustes } \\
\text { rápidos. }\end{array}$ & $\begin{array}{l}\text { Não há a menor idéia } \\
\text { sobre o desempenho do } \\
\text { sistema de produção. }\end{array}$ & $\begin{array}{l}\text { Todos os indicadores } \\
\text { requeridos estão } \\
\text { prontamente } \\
\text { disponíveis. }\end{array}$ & 1 & 5 & 5 & 1 & \\
\hline
\end{tabular}

Quadro 7: Medidas de desempenho 


\section{GESTÃO DA INOVAÇÃO NAS ORGANIZAÇÕES}

A busca constante pela inovação, por meio da criação e desenvolvimento de novos produtos e processos, diversificação, qualidade e absorção de tecnologias avançadas, é indispensável para assegurar elevados níveis de eficiência, produtividade e competitividade das organizações. Isso implica acumulação constante de conhecimentos e capacitação tecnológica contínua. Nesse contexto, insere-se a aprendizagem organizacional (aprendizado contínuo e interativo), configurando-se como o processo mais importante para o desenvolvimento da inovação tecnológica (TOMAÉL; ALCARÁ; DI CHIARA, 2005).

Barbieri et al. (2004) destaca que existem fatores que condicionam a inovação. Os fatores são delimitados pelo modelo de gestão que poderá favorecer o surgimento de inovações. Eles argumentam que motivação, satisfação no trabalho, estímulo à criatividade, redução de conflitos entre gerências, liderança, comunicação interna, gestão de projetos de inovação, empreendedores internos, sistemas de recompensas e clima inovador são alguns temas relacionados com modelos de gestão que interferem em processos de inovação.

Barbieri et al. (2004) afirmam que é difícil manter um ritmo constante de inovações, mesmo de desenvolvimento ou incrementais. Eles sugerem que inovações tecnológicas ou organizacionais processam-se através de formas complexas, envolvendo atividades realizadas por pessoas dentro e fora das organizações, formando redes interpessoais. As condições para que operem de forma mais eficiente e eficaz podem ser conseguidas através da formulação e condução de modelos de gestão para o favorecimento e manutenção de um meio inovador interno, podendo, inclusive, gerar uma cultura de inovação.

Machado e colaboradores (2008) enunciam os fatores condicionantes do meio inovador interno: eficiência percebida com a inovação, incerteza sobre a inovação, escassez de recursos, padronização de procedimentos, grau de influência nas decisões, expectativas de prêmios e sanções, liderança do time de inovação, liberdade para expressar dúvidas e aprendizagem encorajada.

Baranãno (2005) afirma que nenhum elemento isolado tem possibilidade de ser eficaz e, portanto, nenhuma ferramenta ou técnica de gestão cria e sustenta sozinha ambiente propicio à inovação. A inovação é um complexo processo sociológico e econômico que envolve uma teia extremamente intrincada de interações, tanto no interior da empresa como entre estas e o seu contexto econômico, técnico e social. É um conjunto de diferentes fatores inter-relacionados que devem funcionar para criar e reforçar o tipo de ambiente que facilita o sucesso da inovação tecnológica.

Baranãno (2005) considera que o sucesso dos processos de inovação requer como medida básica a criação e manutenção de múltiplos canais de comunicação abertos, bem como de complementar os habituais canais verticais de comunicação, com canais de comunicação hori- 
zontais e diagonais que liguem indivíduos localizados em diferentes unidades organizacionais. A fluidez da comunicação interna e, acima de tudo, a integração de todas as atividades, contribuem para o lançamento de inovações com sucesso, pois garante que todos os esforços apontem numa mesma direção.

A comunicação que se estabelece com o meio não é menos importante, pois garante que os esforços tecnológicos que se estão sendo realizados respondem a uma necessidade existente, ou pelo menos latente, no mercado, para além de ser uma importante fonte de idéias para desenvolvimentos futuros. Assim, pode ser extremamente frutífero estabelecer estreito contacto com clientes, fornecedores e concorrentes. Além disso, por razões de custo ou de complementaridade científico-tecnológica, muitas vezes a organização se vê obrigada a recorrer a fontes externas de conhecimentos.

A comunicação e o estabelecimento de acordos de colaboração com agentes externos exigem determinados requisitos internos, nomeadamente a pesquisa intencional de idéias potenciais, a vontade de compartilhar conhecimentos, abertura para cooperar e um estilo de gestão aberto e descentralizado que permita que a comunicação se produza em todas as direções possíveis e se sirva de múltiplos canais. Ou seja, uma eficaz comunicação interna é requisito indispensável para uma comunicação externa adequada e produtiva (BARANÃNO, 2005).

Lemos (1999) enfatiza que o processo de inovação é um processo de aprendizado interativo, requerendo intensas relações entre diferentes agentes. As relações configuradas como redes devem ocorrer com os agentes internos da organização (indivíduos que atuam em diferentes setores) e, especialmente, com os agentes externos, tais como instituições de pesquisas e universidades, agências governamentais de fomento e financiamento, associações empresariais, organizações não-governamentais, entre outras. A capacidade das organizações se inserirem nessas redes e nesse novo contexto está totalmente atrelada ao investimento da capacitação dos indivíduos, que são os responsáveis pela geração de conhecimentos e inovações.

Tomaél, Alcará e Di Chiara (2005) afirmam que as redes sociais influenciam tanto a difusão de inovações quanto a propagação da informação e do conhecimento que oportuniza o desenvolvimento de inovações. As redes sociais são recursos importantes para a inovação, em virtude de manterem canais e fluxos de informação em que a confiança e o respeito entre atores os aproximam e os levam ao compartilhamento de informações que incide no conhecimento detido por eles, modificando-o ou ampliando-o. As interações possibilitam o compartilhamento de informação e de conhecimento.

Ahuja (2000) estuda como as redes afetam a inovação, e constata que redes fechadas, ou seja, com relacionamentos de compromissos de longo prazo, são propícias para a criação de um ambiente colaborativo e para a superação do oportunismo. Por outro lado, redes com buracos estruturais (isto é, contatos com diversos parceiros que não interagem entre si) facilitam a obten- 
ção de rápido acesso a informações diversificadas. No entanto, os buracos estruturais dificultam a inovação, por prejudicarem a relação de confiança entre os agentes parceiros.

Ahuja (2000) mostra também o efeito das ligações diretas e indiretas no desempenho de inovações. Uma ligação direta é o acesso à empresa com a qual se estabeleceu uma parceria, sendo que tal ligação ocorre sem a intermediação de terceiros. Por outro lado, ligações indiretas são os relacionamentos nos quais a empresa analisada tem algum tipo de acesso indireto a várias empresas, por intermédio de uma empresa com a qual tem parceria direta.

\section{CONSIDERAÇÕES FINAIS}

A discussão das relações entre informação, comunicação e inovação busca desenvolver subsídios para a gestão eficaz da informação para a inovação tecnológica em organizações complexas. A investigação realizada sugere que a Ciência da Informação pode contribuir com o desenvolvimento teórico e metodológico da gestão da inovação das organizações complexas.

Cabe pensar a informação como dinâmica organizacional que abre possibilidades para a criação, a melhoria e a inovação dos processos e produtos. Assim, a gestão da informação é mais do que uma racionalização funcional das ações de informação: pode ser o uso da linguagem como ação comunicativa. A discussão dos processos permanentemente problematizados pode ampliar as possibilidades de interação e colaboração entre os trabalhadores, destes com os gestores, e da organização com o seu entorno.

A colaboração interna e externa facilita não apenas o compartilhamento de informações e conhecimentos, mas também resulta deles. A colaboração viabiliza diálogos, e os diálogos viabilizam colaboração. As organizações não inovam sozinhas, mas sobre informações e conhecimentos acumulados dentro e fora delas. Cabe então pensar nas relações entre comunicação, colaboração e inovação.

A colaboração é condição para a inovação tecnológica, em primeiro lugar para que a informação possa fluir de modo não linear dentro das organizações e entre elas e o seu entorno. A comunicação pode contribuir com idéias e oportunidades para a inovação e na interação entre os colaboradores da organização, ao mesmo tempo em que difunde seus processos e produtos e cria condições para sua aceitação e uso. 


\section{REFERÊNCIAS}

ALBAGLI, Sarita; MACIEL, Maria Lucia. Informação e conhecimento na inovação e no desenvolvimento local. Ciência da Informação, Brasília, v. 33, n. 3, p.9-16, set./dez. 2004.

AHUJA, G. Collaboration Networks, Structural Holes, and Innovation: A Longitudinal Study. Administrative Science Quarterly, v. 45, p. 425-455, 2000.

BARAÑANO, Ana Maria. Gestão da inovação tecnológica: estudo de cinco PMEs portuguesas. Revista Brasileira de Inovação, Rio de Janeiro, v.1, n.2, jan. /jun. 2005.

BARBIERI, J. C. et al. Organizações inovadoras: estudos e casos brasileiros. Rio de Janeiro: Editora FGV, 2004.

BARAÑANO, Ana Maria. Gestão da inovação tecnológica: estudo de cinco PMEs portuguesas. Revista Brasileira de Inovação, Rio de Janeiro, v.1, n.2, jan./jun. 2005.

DOSI, Giovanni. The nature of the innovative process. Technical change and economic theory, London, Pinter. 1982.

DOSI, G. Technical Change and Industrial Transformation. London: Macmillan, 1984.

FUNDAÇÃO CERTI. Fundação Centros de Referência em Tecnologias Inovadoras. Disponível em: <http://www.certi.org.br/>. Acesso em: 10 ago. 2009.

GONZÁLEZ DE GOMEZ, Maria Nélida. Habermas, informação e argumentação. In: COLÓQUIO HABERMAS, 5., 2005, Florianópolis. Anais...Florianópolis: UFSC, 2008.

GONZÁLEZ DE GOMEZ, Maria Nélida. Ciência da informação, economia e tecnologia de informação e comunicação: a informação nos entremeios. In: MACIEL, M.L.; ALBAGLI, S. Informação e desenvolvimento: conhecimento, inovação e apropriação social. Brasília: IBICT/UNESCO, 2007. p. 149-184.

GONZÁLEZ DE GOMEZ, Maria Nélida. O caráter seletivo das ações de informação. Informare, Rio de Janeiro, v. 5, n. 2, p. 7-31, 2000.

HABERMAS, J. Consciência moral e agir comunicativo. Rio de Janeiro: Tempo Brasileiro, 1989.

INOVA SANTA CATARINA (SC). Elementos do processo de inovação. 2007. Disponível em: <www.inovasc.org.br/index.php?option=com_content\&view=article\&id=50\&ltemid > Acesso em: 25 jan. 2009.

KUNZLER, Caroline Morais. A Teoria dos Sistemas de Niklas Luhmann. Estudos de Sociologia, Araraquara, n.16, p. 123-136, 2004. Disponível em:

<http://www.fclar.unesp.br/soc/revista/artigos_pdf_res/16/07kunzler.pdf>. Acesso em: 04 nov. 2008.

LEMOS Cristina. Inovação na era do conhecimento. In: LASTRES, Helena M. M; ALBAGLI, Sarita. Informação e globalização na era do conhecimento. Rio de Janeiro: Campus, 1999. p. 122-144.

LUHMANN, Niklas. Sistema y función. In: IZUZQUIZA, Ignacio (org). Sociedad y systema: la ambición de la teoría. Barcelona: Ediciones Piado Barcelona, 1990. 
LUHMANN, N. A. Sistemas sociológicos: lineamentos para una teoría general. Madrid: Alianza Editorial/Universidad Iberoamericana, 1991.

LYYTINIEN, K. Two views of information modeling. Information and Management, n.12, p. 9-19, 1987.

MACHADO, Denise Del Prá Netto; LEHMANN, Cristiane Arndt; ARAUJO, Bárbara de. Organização e cultura de inovação: elementos concretos e fatores percebidos. Revista Alcance, v. 15, n, 2, p.152-168, mai/ago. 2008.

MELHADO, José P. Disseminação e proteção de informações no processo de inovação tecnológica um estudo do contexto regulatório aplicado ao caso brasileiro. Dissertação. 2005 (Mestrado em Ciência da Informação). Pontifícia Universidade Católica. Campinas, 2005. 123p.

NYSTRÖM, H. Technological and market innovation: strategies for product and company development. London; New York: John Wiley \& Sons. 1993.

OCDE. Manual de Oslo: proposta de diretrizes para coleta e interpretação de dados sobre inovação tecnológica. Tradução da Financiadora de Estudos e Projetos. Paris: OCDE, 2004.

SCHUMPETER, J. Capitalismo, Socialismo e Democracia. Tradução de Ruy Jungmann. Rio de Janeiro: Ed. Fundo de Cultura, 1961. 512p.

TOMAÉL, Maria Inês; ALCARÁ, Adriana Rosecler, DI CHIARA, Ivone Guerreiro. Das redes sociais à inovação. Ciência da Informação, Brasília, v. 34, n. 2, p. 93-104, maio/ago. 2005.

\title{
Title
}

Information, communication and innovation: information management for innovation in a complex organization

\begin{abstract}
The article addresses the relationship between information, communication and technological innovation in CERTI Foundation, linked to the Federal University of Santa Catarina, based on concepts and critical approaches from the Information Science. It presents a discussion of the relationship between information and innovation. It argues from Habermas' Theory the collaboration in organizations as an essential condition in complex dynamics that lead, produce and incorporate innovations, as well as assumptions of technological innovation management are discussed. The research methods included, in addition to the literature, a documental study on CERTI foundation and interviews based on a structured questionnaire. The results show the information and communication's relevance for collaboration and innovation. It concludes that a proper information and communication management can contribute to efficiency and innovation in complex organizations, particularly in institutes of scientific research and technology.
\end{abstract}

\section{Keywords}

Information Management. Communication. Innovation. 


\section{Título}

Información, comunicación e innovación: gestión de la información para innovación en una organización compleja

\section{Resumen}

En este artículo se discuten las relaciones entre la información, la comunicación y la innovación tecnológica en la Fundación CERTI (Centros de Referência em Tecnologias Inovadoras), vinculado a la Universidade Federal de Santa Catarina. Hace uso de conceptos y de abordages críticas de la Ciencia de la Información. Se presenta um análisis de la relación entre la información y la innovación. Se argumenta, desde la Teoría de la Acción Comunicativa de Habermas, la colaboración en las organizaciones como condición para dinámicas complejas que inducen, producen e incorporan las innovaciones. Se discuten los presupuestos de una gestión de la innovación tecnológica. Los métodos de investigación utilizados incluyen, ademas de la literatura, el estudio en la Fundación CERTI, con recuperación de documentos y entrevistas con cuestionario estructurado. Los resultados evidencian la pertinencia de la información y la comunicación para la colaboración y la innovación. Se concluye que la gestión adecuada de la información y la comunicación puede contribuir a la eficiencia y la innovación en organizaciones complejas, em particular em los institutos de investigación cientifica y tecnológica.

\section{Palabras clave}

Gestión de la información. Comunicación. Innovación.

Recebido em: 11.10.2009

Aceito em: 01.11.2009 